\title{
Aronia melanocarpa Fruit and Leaves Hot-Assisted Ethanolic Extracts Antioxidant Activity ${ }^{\dagger}$
}

\author{
Andrei Munteanu 1, Alin Enache 1, Georgeta Neagu 2, Corina Bubueanu 2, Alice Grigore 2, \\ Nicoleta Rusu ${ }^{2}$ and Lucia Pirvu ${ }^{2, *}$ \\ 1 Apel Laser SRL, 15 Vintila Mihailescu, 060394 Bucharest, Romania; andrei.munteanu@apellaser.ro (A.M.); \\ alin.enache@apellaser.ro (A.E.) \\ 2 National Institute of Chemical Pharmaceutical R\&D, ICCF, 112 Vitan, 031299 Bucharest, Romania; \\ getabios@yahoo.com (G.N.); corina.bubueanu@yahoo.com (C.B.); alicella77@yahoo.com (A.G.); \\ ninarusu55@yahoo.com (N.R.) \\ * Correspondence: lucia.pirvu@yahoo.com \\ + Presented at the 16th International Symposium "Priorities of Chemistry for a Sustainable Development" \\ PRIOCHEM, Bucharest, Romania, 28-30 October 2020.
}

Published: 12 November 2020

Keywords: Aronia melanocarpa L.; hot-assisted ethanolic extracts; antioxidant activity

\section{Introduction}

Aronia melanocarpa L. fruit (common black chokeberry) is one of the most abundant sources of antioxidant compounds in the plant world, superior to all edible fruits; chokeberry fruits contain up to $100 \mathrm{~g}$ total phenols per $\mathrm{kg}$ fresh material, predominantly (-)epicatechin, cyanidin-3-glycosides and procyanidins (60\%), added to quercetin and caffeoyl quinic acid derivates. Alongside this, chokeberry leaves contain up to $15 \mathrm{~g}$ total phenols per $\mathrm{kg}$ fresh material, predominantly hyperoside, isoquercitrin, rutin and caffeic acid and chlorogenic acid [1,2]. Among potential human health benefits, Aronia melanocarpa-derived products were proved with antioxidant and anti-inflammatory effects, anti-diabetic, anti-lipidemic, cardio-protective, anti-hypertensive and platelet anti-aggregating effects, hepato-protective and gastro-protective effects, cognitive-enhancing and behavioral effects, and antibacterial, antiviral, immunomodulatory and radioprotective effects [1,2]. The present work aims to study antioxidant activity of two hot-assisted etanolic extracts from chokeberry fruit and chokeberry leaf plant parts, respectively; antioxidant activity was compared with two reference compounds (ref.) and several plant extracts obtained under similar study conditions [3].

\section{Materials and Methods}

Aronia melanocarpa L. fruit and leaves plant parts were collected in 2019 from a plantation situated in Prahova region, Romania. Antioxidant activity screening has been done using chemiluminescence method (CL), luminol $-\mathrm{H}_{2} \mathrm{O}_{2}$ system, $\mathrm{pH}=8.9$ [3].

\section{Results}

The hot-assisted $(70 \%, v / v)$ ethanolic extraction of chokeberry fruits leads to extracts with low antioxidant activity ( $\mathrm{IC}_{50}=25 \mu \mathrm{g}$ GAE/mL extract, Figure 1$)$, most likely due to the polymerization of the anthocyanins contained, resulting in high molecular compounds which are less effective as reactive oxygen species scavenging activity. Conversely, the hot-assisted $(70 \%, v / v)$ ethanolic extraction of chokeberry leaf plant part leads to extracts with very high antioxidant activity 
( $\mathrm{IC}_{50}=0.625 \mu \mathrm{g} \mathrm{GAE} / \mathrm{mL}$, Figure 2); by comparison, gallic acid and rutin (ref.) shown $\mathrm{IC}_{50}=0.85 \mu \mathrm{g}$ $\mathrm{GAE} / \mathrm{mL}$ and $\mathrm{IC}_{50}=2.54 \mu \mathrm{g} \mathrm{GAE} / \mathrm{mL}$.

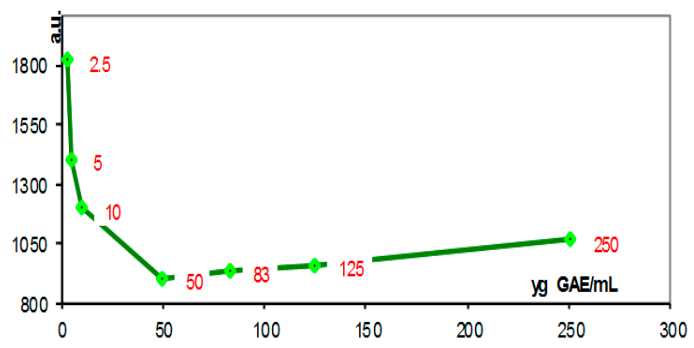

Figure 1. IC 50 assay on chokeberry fruit. Hot-assisted ethanolic extract.

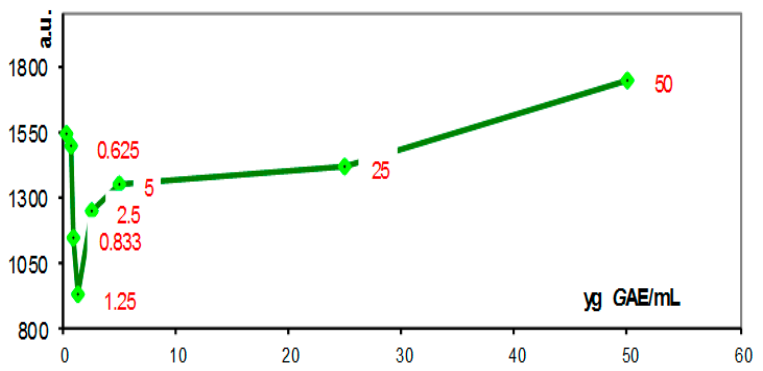

Figure 2. IC50 assay on chokeberry leaves. Hot-assisted ethanolic extract.

\section{Conclusions}

Compared to other vegetal extracts [3], Aronia leaves' ethanolic extract ranks as one of the most efficient antioxidant products, suggesting high utility as a medicinal and cosmetic ingredient.

Acknowledgments: This research received no external funding; the APC was funded by the ANCSI POC-A1-A1.2.3-G-2015, "New technologies and natural products for human health use", Contract 60/05.09.2016, ID P_40_406, SMIS 105542, Contract D no. 35/08.11.2019.

\section{References}

1. Nowak, D.; Goslinski, M.; Wojtowicz, E. Comparative Analysis of the Antioxidant Capacity of Selected Fruit Juices and Nectars: Chokeberry Juice as a Rich Source of Polyphenols. Int. J. Food Prop. 2016, 19, 1317-1324.

2. Kokotkiewicz, A.; Jaremicz, Z.; Luczkiewicz, M. A Review of Traditional Use, Biological Activities, and Perspectives for Modern Medicine. J. Med. Food 2010, 13, 255-269.

3. Pirvu, L.; Sha'at, F.; Miclea, L.C.; Savopol, T.; Neagu, G.; Udeanu, D.I.; Moisescu, M.G. Polygonum bistorta L. herba et flores. Polyphenols profile, antioxidant properties and cytotoxic effect on murine fibroblast cell line (NIH 3T3). Farmacia 2017, 65, 571-576.

Publisher's Note: MDPI stays neutral with regard to jurisdictional claims in published maps and institutional affiliations.

(C) 2020 by the authors. Licensee MDPI, Basel, Switzerland. This article is an open access article distributed under the terms and conditions of the Creative Commons Attribution (CC BY) license (http://creativecommons.org/licenses/by/4.0/). 